\title{
Profiling of oxygen in biofilms using individually addressable disk microelectrodes on a microfabricated needle
}

\author{
Ana Moya ${ }^{a, e, \dagger}$, Xavier Guimerà ${ }^{\mathbf{b}, \dagger}$, Francisco Javier del Campo ${ }^{a}$, \\ Elisabet Prats-Alfonso ${ }^{a, e}$, Antonio David Dorado ${ }^{b}$, Mireia Baezac $^{c}$, Rosa Villa $^{a, e}$, \\ David Gabriel $^{\mathrm{d}}$, Xavier Gamisans ${ }^{\mathrm{b}}$, Gemma Gabriel ${ }^{\mathrm{a}, \mathrm{e}, * 1}$
}

${ }^{a}$ Instituto de Microelectrónica de Barcelona, IMB-CNM (CSIC), Esfera UAB, Campus Universitat Autònoma de Barcelona, 08193Bellaterra, Barcelona, Spain

${ }^{b}$ Department of Mining Engineering and Natural Resources, Universitat Politècnica de Catalunya, Avinguda de les Bases de Manresa 61-73, 08240 Manresa, Spain

${ }^{c}$ Department of Chemistry, Facultat de Ciències, Edifici C-Nord, Univeritat Autònoma de Barcelona, 08193 Bellaterra, Barcelona, Spain

${ }^{d}$ Department of Chemical Engineering, Universitat Autònoma de Barcelona, EdificiQ, 08193 Bellaterra, Barcelona, Spain

${ }^{e}$ Biomedical Research Networking Center in Bioengineering, Biomaterials and Nanomedicine (CIBER-BBN),Zaragoza, Spain

\begin{abstract}
A novel microelectrode array sensor was fabricated using MEMS technology on a needle, and then applied to real-time measurement of dissolved oxygen (DO) inside biofilms. The sensor consists of eleven gold disk microelectrodes and a rectangular auxiliary electrode along them and an external \& internal reference electrode. Three kinds of sensors were designed and their responses were characterized and evaluated under various environmental conditions. The arrays exhibit a linear response to DO in the 0 - $8 \mathrm{mg} \mathrm{L}^{-1}$ concentration range in water, high sensitivity, repeatability, and low limits of detection $\left(<0.11 \mathrm{mg} \mathrm{L}^{-1}\right)$ and quantification $\left(0.38 \mathrm{mg} \mathrm{L}^{-1}\right)$. The sensors were then validated against a commercial Clark-type microelectrode and applied to profiling of DO in a heterotrophic biofilm cultivated in a flat-plate bioreactor. It is shown that the sensor array can provide a multipoint, simultaneous snapshot profile of DO inside a biofilm with high spatial resolution due to its micrometric dimensions. We conclude that this new sensor array represents a powerful tool for sensing of DO biofilms and in numerous bioprocesses.
\end{abstract}

Keywords: Dissolved Oxygen; Microelectrode Array; Sensors; Bioprocess Monitoring; Biofilms;

Runing title: Profiling of oxygen in biofilms using microelectrodes

\footnotetext{
* Corresponding author. Tel.: +34 9359477 00x2506 fax: +34 9358002 67. E-mail address: gemma.gabriel@imb-cnm.csic.es

${ }^{7}$ These authors contributed equally to this study.
} 


\section{Introduction}

Biofilm formation affects most waste-water and waste-gaseous treatment processes. Both treatment bioreactors use biofilms to remove pollutants [1,2], it is therefore critical in bio-reactor design to understand the phenomena and mechanisms governing biofilm growth dynamics.

Among the many chemical species that can be found and monitored inside biofilms, oxygen is perhaps the most important, as it is the primary electron acceptor in most aerobic biological processes. The local concentration of oxygen inside a biofilm reveals the existence of different zones [3], either aerobic or anaerobic, which can explain the biodegradation processes linked to characteristic oxygen profiles. In addition, knowledge of oxygen concentration gradients allows the description of mass transfer [4] and biokinetics [5] processes, allowing the development of more rigorous models.

When characterizing biofilms [6], microsensors are suitable powerful tools for the determination of chemical parameters with a high spatial resolution. In the measurement of dissolved oxygen, the most widely used analytical methods are based on fiber-optic [7] and electrochemical [8] microsensors. Both techniques are implemented in several applications, including waste-water oxygen analysis [3] because of their ability to make real time and continuous measurements in small volumes. Features of optical sensors include chemical inertness, internal reference, stability, high sensitivity to small oxygen concentration changes and flow-rate independence [7]. The amperometric method, on the other hand, affords simplicity of operation, high sensitivity and high design flexibility.

Clark-type microsensors [8] are the most electrochemical commonly used probes and at the present considered the gold standard [9] in biofilm oxygen sensing. Such DO sensors consist of an electrochemical three-electrode system with a reference electrode (RE), an auxiliary/counter electrode (CE) and a working electrode (WE) in an aqueous solution. Such three-electrode system is isolated from the medium by a selective gaspermeable membrane across which oxygen diffuses towards the cathode (WE), at a rate proportional to its partial pressure. Thus the reduction current generated at the cathode is directly proportional to the oxygen concentration in the test solution. The working electrode potential is typically set around $-800 \mathrm{mV}$ (vs $\mathrm{Ag} / \mathrm{AgCl}$ ) so that the overall reaction (eq. 3) can take place following two consecutive two-electron reduction steps [10]:

$$
\begin{aligned}
& \mathrm{O}_{2}+2 e^{-}+\mathrm{H}_{2} \mathrm{O} \rightarrow \mathrm{HO}_{2}^{-}+\mathrm{OH}^{-} \\
& \frac{\mathrm{HO}_{2}^{-}+2 e^{-}+\mathrm{H}_{2} \mathrm{O} \rightarrow 3 \mathrm{OH}^{-}}{\mathrm{O}_{2}+4 e^{-}+2 \mathrm{H}_{2} \mathrm{O} \rightarrow 4 \mathrm{OH}^{-}}
\end{aligned}
$$

Clark-type microsensors have been widely used to monitor biofilms and sediments [11, 12]. However, their manufacture presents important limitations [13]. Most of these sensors are hand crafted from pulled glass capillaries, and so their main limitations are the fragility and high unit cost of the devices, the tip-size variability between different 
probes, and the difficulty to bundle several microelectrodes in arrays of controlled geometry.

Another limitation shared by Clark-type microsensors and optical sensors lays on the fact that they are restricted to single point measurements performed one at a time, which makes the acquisition of DO profiles inside biofilms extremely tedious and inaccurate. Important efforts have been made in the past to measure DO profiles in biofilms [1416], some of them based on microfabricated microneedles [17]. The reported profiles are obtained by mounting the microelectrode on a micromanipulator and driving it into the biofilm in a series of recording and penetration steps.

Microfabrication techniques represent a much more versatile approach to microelectrode design, enabling the fabrication of electrodes of wide ranging sizes, geometries and arrangements. Thus, it is possible to create nano- and microelectrodes and their arrays [18-21], including disks [20, 22], bands [23, 24] and 3D structures [2527], and wire them either in parallel or individually $[18,20]$. On top of that, microfabrication techniques allow the cost-effective mass-production of microsensors that can be deployed in a vast number of applications.

The device presented in this work enables the determination of the oxygen concentration profile within a biofilm by simultaneously measuring the oxygen consumption at different depths inside it. This novel DO-MEA sensor to measure DO profiles overcomes the limitations presented both by optical and Clark-type microsensors by producing multipoint, instant DO measurements in biofilms in-situ. Amperometric techniques enable these simultaneous measurements in a simple way.

\section{Materials and methods}

Reagents and instrumentation

All solutions used in the sensor development were prepared with deionized water (conductivity less than $1 \mu \mathrm{S} \cdot \mathrm{cm}^{-1}$ ). Chemicals used $\left(\mathrm{K}_{3}\left[\mathrm{Fe}(\mathrm{CN})_{6}\right], \mathrm{K}_{4}\left[\mathrm{Fe}(\mathrm{CN})_{6}\right], \mathrm{KNO}_{3}\right.$, $\mathrm{KOH}, \mathrm{H}_{2} \mathrm{O}_{2}$ and $\mathrm{Na}_{2} \mathrm{SO}_{3}$ ) were of analytical grade and used as received from (SigmaAldrich, www.sigmaaldrich.com), without further purification.

Microelectrode characterization and sensor calibration were carried out with an 8channel potentiostat 1030A Electrochemical Analyzer (CH-Instruments, USA; http://chinstruments.com). Control experiments were performed using a commercial $\mathrm{Ag} / \mathrm{AgCl}(3 \mathrm{M} \mathrm{KCl})$ electrode as $\mathrm{RE}$ and a platinum ring electrode as $\mathrm{CE}$ both from (Metrohm, Germany; www.metrohm.com). However, the RE and the CE incorporated in the microsensor needle were also used in the profiling experiments. The microfabricated sensors were calibrated in controlled dissolved oxygen solutions against an OXI 325 (WTW, Germany; http://www.wtw.de) oxygen probe.

A Clark-type commercial microelectrode (OX-25, Unisense, Denmark, www.unisense.com) with a tip diameter of $25 \mu \mathrm{m}$, connected to a 4-channel amplifier 
Microsensor Multimeter (Unisense, Denmark) was used for biofilm profiling in control experiments. Profiles were obtained with the aid of a micromanipulator MM33-2 (Unisense, Denmark).

\section{Calibration of DO-MEA sensor}

Microelectrodes (microfabrication process description is detailed in the Electronic Supporting Information, Fig. S1) required activation before use. Several known goldcleaning methods were investigated [28]. Adequate electrode activation was indicated by $\mathrm{Ip}$ and $\Delta \mathrm{E}_{\mathrm{p}}$ values consistent with reversible electrode kinetics [29] (electrode preparation is detailed in the Electronic Supporting Information).

Sensors were calibrated in the oxygen concentration range between 0 and $8 \mathrm{mg} \mathrm{DO} \cdot \mathrm{L}^{-1}$ range according to [30]. Oxygen was measured amperometrically using a set-up Fig. S2 (Electronic Supporting Information). The sensor was polarized at $-850 \mathrm{mV}$ vs $\mathrm{Ag} / \mathrm{AgCl}$ ( $3 \mathrm{M} \mathrm{KCl})$. The DO concentration was adjusted bubbling different nitrogen $\left(\mathrm{O}_{2}\right.$ free) air $\left(21 \% \mathrm{O}_{2}\right)$ mixtures through a $0.1 \mathrm{M} \mathrm{KNO}_{3}$ solution, and a magnetic stirrer was used to ensure better mixing of the solution.

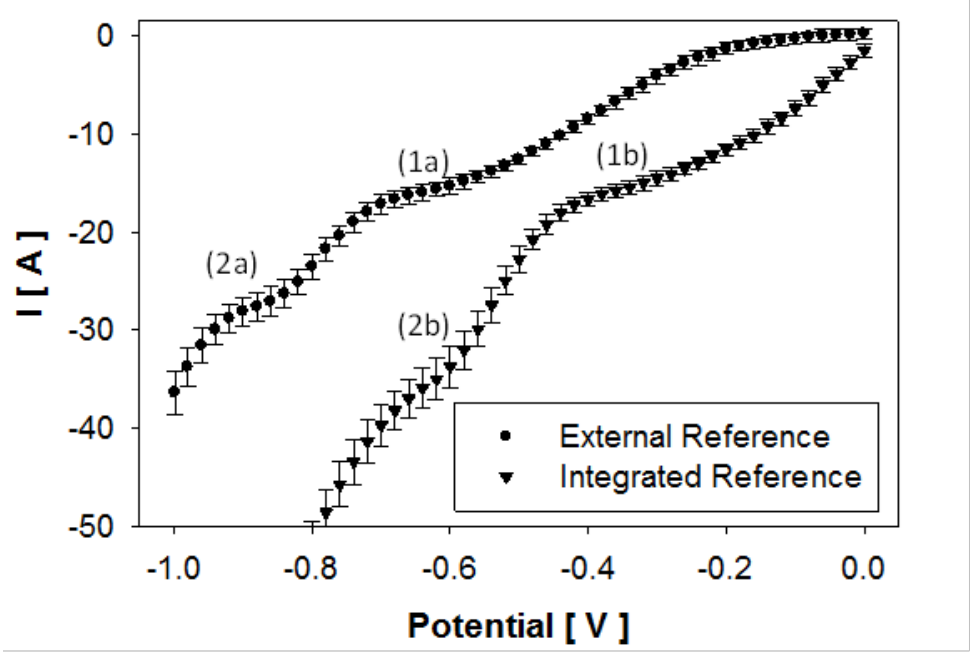

Fig. 1 Linear sweep voltammetry results. Average of measured currents and their standard deviation plotted against the potential applied on eight WE against the external $(\bullet)$ and the integrated three-electrode reference system $(\boldsymbol{\nabla})$. Linear sweeps were made in an oxygen saturated saline solution ( $\left.8 \mathrm{mg} \mathrm{DO} \cdot \mathrm{L}^{-1}\right)$. First (1) and second (2) reduction peaks can be observed in linear sweep voltammograms both with an external reference and with an integrated reference.

Fig. 1 shows linear sweep voltammograms from 0 to $-1 \mathrm{~V}$ at a scan rate of $25 \mathrm{mV} \cdot \mathrm{s}^{-1}$ in a $8 \mathrm{mg} \mathrm{DO} \cdot \mathrm{L}^{-1}$ oxygen solution using the commercial $\mathrm{Ag} / \mathrm{AgCl}(3 \mathrm{M} \mathrm{KCl}) \mathrm{RE}$ and $\mathrm{Pt}$ $\mathrm{CE}$, and with both integrated in the needle Au microelectrode array. The figure shows 
that the two signals are shifted about $250 \mathrm{mV}$ due to the use of different reference electrodes. The difference in the limiting currents values of the second step was because different needles were used, with small differences depending on their state of activation.

These voltammograms allowed us to select the $-850 \mathrm{mV}$ vs $\mathrm{Ag} / \mathrm{AgCl}$, operating with the external reference system, and $-600 \mathrm{mV}$ vs Au for the integrated three-electrode system, as the optimal potential value for the determination of the dissolved oxygen concentration (Fig. 1). This is because that potential involves the complete four electron reduction of oxygen, and therefore a higher sensitivity. Note that at this potential the hydrogen evolution reaction does not take place at a significant rate and therefore does not interfere with the main process under study.

The concentration of DO in the cell was measured with a commercial DO probe and correlated with the measured polarization currents of each gold microelectrode in order to build the calibration curves.

\section{Growth of an aerobic biofilm}

The suitability of the DO-MEA sensor for biofilm profiling of an aerobic biofilm was checked comparing the response of the microfabricated sensor with that of a commercial DO Clark-type microsensor. A flat plate bioreactor (FPB) was designed and constructed as in Fig. S3 (Electronic Supporting Information) to grow a well-defined biofilm. The FPB was designed according to [31], and was manufactured in PMMA. The reactor consisted of an open channel of $20 \mathrm{~cm}$ length and $3.5 \mathrm{~cm}$ width. Inoculation was performed by filling the channel with $35 \mathrm{~mL}$ of sludge of $2 \mathrm{~g} \mathrm{SSV} \cdot \mathrm{L}^{1}$ from a pilot plant bioreactor treating synthetic waste-water.

A mineral medium solution (prepared according to [32]) was supplied to the reactor using glucose as carbon source. The hydraulic residence time ranged from 4 to 8 hours throughout the FPB operation. The FPB included an internal recycle flow within the reactor corresponding to a linear velocity between 0.1 to $10 \mathrm{~m} \cdot \mathrm{h}^{-1}$. Two peristaltic pumps (MCP Standard, Ismatec, Germany) fed and purged the reactor, while a Miniplus 3 peristaltic pump (Gilson, France) was used for internal recirculation.

DO profiles were recorded directly on the biofilm growing in the reactor using both microsensors. DO-MEA sensor profiles were obtained immersing the sensor, the RE and the CE into the biofilm and keeping it still during amperometric recording. The recording time was 15 seconds for an 8-points profile. Clark-type microsensor profile registration was carried in a similar manner. Probe position was controlled by a micromanipulatior, but a multimeter was used instead of a potentiostat to monitor its response. The measurement time depends on the depth of the profile; each step on the profile requires 15 seconds of acquisition plus the time required for changing position within the biofilm. 


\section{Results and discussion}

Amperometric DO determination

The oxygen reduction amperometric signal is affected by medium composition (particularly $\mathrm{pH}$ ) and also by the electrocatalytic properties of the microelectrodes, which can be improved thorough the activation procedures described above. In a first stage, the response was characterized using external reference and auxiliary electrodes. Following this, the measurements were repeated using the auxiliary and pseudoreference electrodes integrated in the needle. The measurement system had not much noise and the use of a Faraday cage was not necessary, making easier the biofilm profiling monitoring in the FPB.

\section{DO-MEA sensor activation and electrochemical characterization}

Electrodes were activated as described in the section Electrode Preparation (Electronic Supporting Information). After activation, the DO-MEA sensor was characterized using cyclic voltammetry in a ferro/ferri cyanide solutions from $500 \mathrm{mV}$ to $-200 \mathrm{mV}$, at a scan rate of $100 \mathrm{mV} \cdot \mathrm{s}^{-1}$. The stability and durability of the electrodes after activation was evaluated by the continuous monitoring of the voltammogram Ip over a period of thirtyfive days. The objective of this test was to study the reproducibility and stability of the DO-MEA sensor response of two sets: a) electrodes activated only the first day and b) electrodes reactivated on a daily basis.

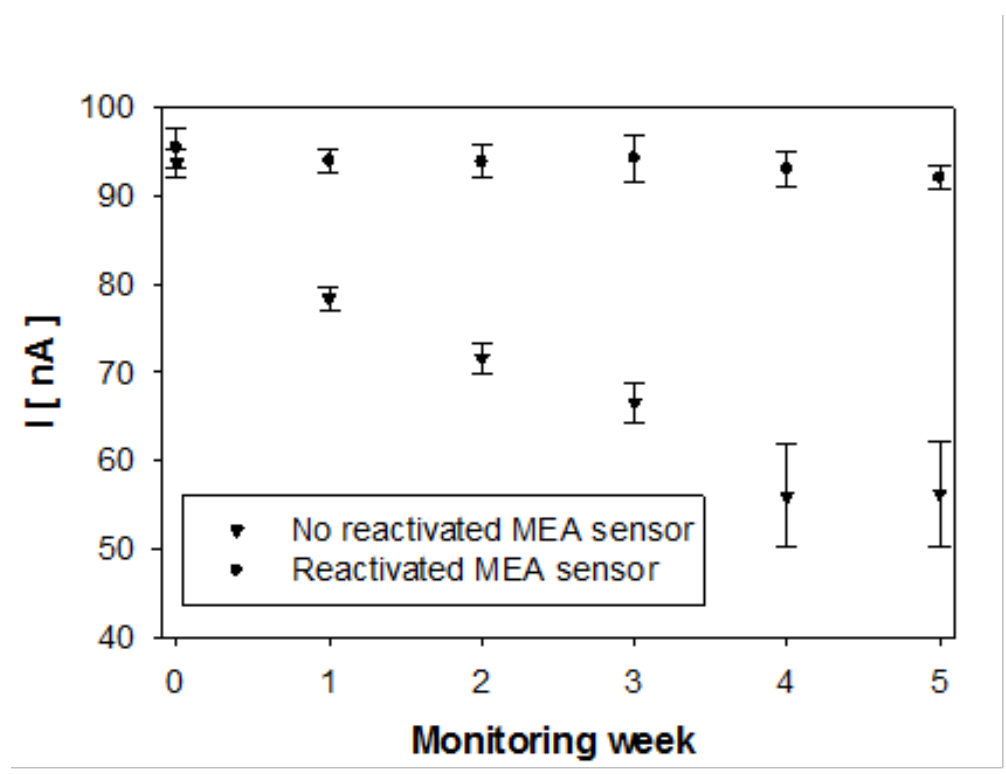

Fig. 2 Evaluation of the activation stability for a reactivated needle $(\bullet)$ and other no reactivated $(\boldsymbol{\nabla})$. The oxidation current peak of the voltammogram corresponds to the average and the standard deviation of 8 electrodes of the same DO-MEA sensor.

Fig. 2 shows the evolution of the ferro/ferri cyanide reduction peak current of two different needles. The electrodes of the daily reactivated needle recovered their optimum response (Ip within $\pm 1.8 \%$ ) with the maximum sensitivity evaluated later 
with the calibration curve. On the other hand, the needle that was not reactivated throughout the testing period lost sensitivity over time, and after five weeks their Ip decreased down to $40 \%$ of the initial, optimum state. In addition, the standard deviation between electrodes of the Ip value of these electrodes response increased as time passed. This activity loss was due to electrode fouling caused by the biofilms tested. However, despite sensitivity losses, the sensor continued responding to changes in DO concentration. Because the application presented in this work does not required continuous measurements, it was possible to activate the electrodes before each day of experiments to ensure maximum sensor performance for each profile acquired.

\section{DO-MEA sensor calibration}

The linearity and sensitivity of the electrochemical response of the three different DOMEA sensors designs were verified in the calibration medium $0.1 \mathrm{M} \mathrm{KNO}_{3}$ by bubbling a series of nitrogen/air gas mixtures as detailed in section of biofilm DO profile study. Figure 4 summarizes the reduction currents measured at microelectrodes of different size under different DO concentrations. The points represent the average from the eight different microelectrodes on each needle, and the error bars represent standard deviation arising from the eight microelectrodes. These results were measured simultaneously using the 8-channel multipotentiostat with the external reference electrode.

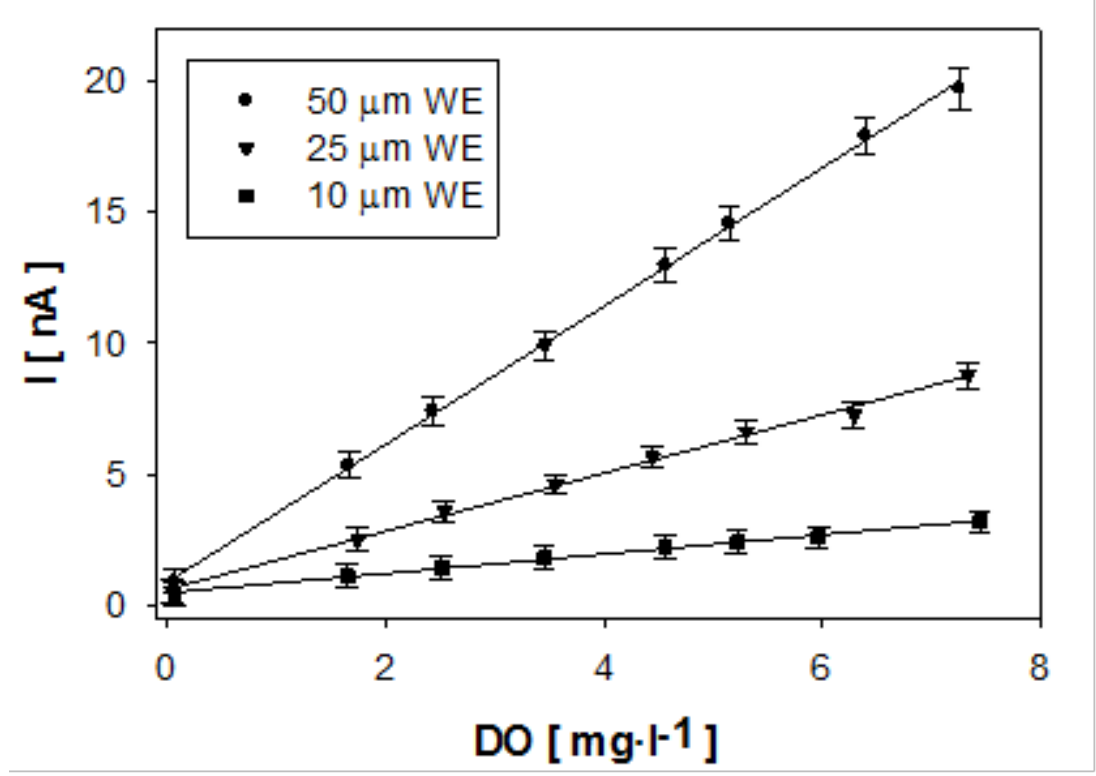

Fig. 3 Calibration curves obtained for the reduction of oxygen for the three different designs. Currents were measured at $-850 \mathrm{mV}$ vs. Ag/AgCl RE and Pt CE. The points correspond to the average current and the standard deviation for eight different electrodes of the same DO-MEA sensor. 
The sensors displayed excellent linearity between $0-8 \mathrm{mg} \mathrm{DO} \cdot \mathrm{L}^{-1}$ range with correlation factors $\left(r^{2}\right)$ greater than 0.99 for all three microelectrodes sizes, demonstrating that the sensors are suitable for the determination of DO.

In addition to the calibration curves, the DO concentrations can be estimated experimentally from the microelectrode calibration response, or theoretically from the equation corresponding to a diffusion controlled limiting current ( $\mathrm{I}_{\mathrm{lim}}$ ) (defined in Electronic Supporting Information).

The experimental results in $0.1 \mathrm{M} \mathrm{KNO}_{3}$ were in good agreement with current values obtained from eq. (S2), considering a passivation recess height of $1.9 \mu \mathrm{m}$. The experimental obtained sensitivities were: for the electrode diameter of $50 \mu \mathrm{m}, 2.41 \pm$ $0.08 \mathrm{nA} \cdot \mathrm{L} \cdot \mathrm{mg}^{-1} \mathrm{DO}$; for the electrode diameter of $25 \mu \mathrm{m}, 1.10 \pm 0.08 \mathrm{nA} \cdot \mathrm{mg} \mathrm{DO}^{-1} \cdot \mathrm{L}$ and for the smallest diameter of $10 \mu \mathrm{m}, 0.35 \pm 0.02 \mathrm{nA} \cdot \mathrm{mg} \mathrm{DO}^{-1} \cdot \mathrm{L}$. In terms of current density (j), the obtained values were: $\mathrm{j}_{50 \mu \mathrm{m}}=1.23 \mathrm{~A} \cdot \mathrm{m}^{-2}, \mathrm{j}_{25 \mu \mathrm{m}}=2.24 \mathrm{~A} \cdot \mathrm{m}^{-2}$ and $\mathrm{j}_{10 \mu \mathrm{m}}=$ 4.46 A $\cdot \mathrm{m}^{-2}$, where smaller electrodes sizes display higher current densities thanks to the greater contribution of hemispherical diffusion to their edges. Approximately thirty DOMEA sensors (twenty for the design with bigger electrodes, and five of other types each) were calibrated and all showed good reproducibility with a standard deviation between microelectrodes less than $0.08 \mathrm{nA} \cdot \mathrm{mg} \mathrm{DO}^{-1}$. This analysis was completed studying the repeatability of the measurement resulting in a good behavior. Besides the effect of the overlapping neighboring electrodes diffusion layers in the array [18, 20, 33] was also considered, and the separation between electrodes was decided in order to minimize this effect. This effect was higher for smaller DO-MEA design, where interelectrodes distance was $35 \mu \mathrm{m}$, and was minimized for the bigger design with an interelectrode distance of $100 \mu \mathrm{m}$.

Although the intercepts shown in Fig. 3 are very close to zero, sensors response showed a residual current in absence of oxygen which could be caused either by the presence of residual DO due the limited efficiency of the deoxygenation procedure, or by a current due to the onset of the hydrogen reduction on the electrodes surface, since the working potential selected is limiting at the reaction as was illustrated in section of biofilm DO profile study. This offset was approximately $1 \mathrm{nA}$ for the $50 \mu \mathrm{m}$ design, $0.65 \mathrm{nA}$ for the $25 \mu \mathrm{m}$ electrode and $0.48 \mathrm{nA}$ for the $10 \mu \mathrm{m}$ design.

Other important parameters worth taking into account are the limits of detection and quantification defined by IUPAC (defined in Electronic Supporting Information). Table 1 shows the $L_{D}$ and $L_{Q}$ values according eq. S3 and eq. S4 obtained experimentally for the three different designs. Overall, calibration tests revealed a high sensitivity and repeatability and low detection and quantification limits of the developed sensors.

Table 1. Limit of detection and Limit of quantification for the three different designs.

\begin{tabular}{ccc}
\hline Microelectrode diameter $/ \boldsymbol{\mu m}$ & $\mathbf{O}_{\mathbf{2}} \mathbf{L}_{\mathbf{D}} / \mathbf{~ m g ~ L ~}^{-\mathbf{1}}$ & $\mathbf{O}_{\mathbf{2}} \mathbf{L}_{\mathbf{Q}} / \mathbf{~ m g ~ L ~}^{-\mathbf{1}}$ \\
\hline $\mathbf{5 0}$ & $0.04 \pm 0.01$ & $0.15 \pm 0.03$ \\
$\mathbf{2 5}$ & $0.07 \pm 0.02$ & $0.22 \pm 0.08$ \\
\hline
\end{tabular}


Three-point calibration curves of the DO-MEA were made in the mineral medium used for biofilm growth (data not shown) with respect to a $\mathrm{Ag} / \mathrm{AgCl}$ external reference electrode before and after each experimental biofilm profile monitoring. The sensor performed linearly as in $\mathrm{KNO}_{3}$ and exhibited a sensitivity of $2.36 \pm 0.09 \mathrm{nA} \cdot \mathrm{L} \cdot \mathrm{mg}^{-1}$ DO. This $2 \%$ lower sensitivity confirms the good performance of the device for this application. Furthermore, its applicability without covering the electrode with an oxygen-permeable membrane, as is usually done in the Clark-type sensors, provides advantages over the protected ones as higher sensitivity and faster response.

\section{Effect of the mineral medium in the DO-MEA microsensor response}

In order to determine the working range of the sensors, their response in media of different composition was also studied. The effects of mineral medium composition and of $\mathrm{pH}$ on the DO-MEA sensor performance are detailed in the Electronic Supporting Information. Results in Fig. S4 (Electronic Supporting Information) indicate that changing the salt anion of the supporting electrolyte has no effect on the sensor sensitivity, however, changes in ionic strength significantly affected the sensor response. In addition, the oxygen signal was nearly unaffected by $\mathrm{pH}$ changes in the $6<\mathrm{pH}<8$ range (Table $\mathrm{S} 1$ in the Electronic Supporting Information).

Needle integrated three-electrode system

Since biofilm thickness may range from several microns to a few millimeters and biofilms are often grown in small reactors in order to study them, it is necessary to integrate the $\mathrm{RE}$ and the $\mathrm{CE}$ in the needle avoiding external electrodes and, thus, reducing the experimental system dimensions. At this stage, one of the integrated microdisk electrodes in the DO-MEA was used as pseudo-reference electrode while the rectangular macroelectrode was used as $\mathrm{CE}$. The main difference introduced with the integrated three-electrode system configuration was that the reduction potential shifts \pm $250 \mathrm{mV}$. The different studies, described in the previous section for the external reference system, were carried out with the integrated three-electrode system, obtaining the same sensor behavior. In order to improve the stability of the pseudo-reference, the electrode surface was previously oxidized, subjected it to a continuous anodization, so that it would keep a more stable potential over time [34]. The oxidized pseudo-reference electrode was evaluated with a continuous measurement of its potential versus a commercial $\mathrm{Ag} / \mathrm{AgCl}(3 \mathrm{M} \mathrm{KCl})$ electrode in $\mathrm{KNO}_{3} 0.1 \mathrm{M}$ for $18 \mathrm{~h}$. The drift rate of the integrated reference was $0.68 \mathrm{mV} \cdot \mathrm{h}^{-1}$, which was considered acceptable for short-term measurements such as those conducted in the present study. However, long-term measurements require a reference with a lower drift, which will be achieved in future work, using an integrated $\mathrm{Ag} / \mathrm{AgCl}$ reference. The calibration of the integrated threeelectrode system microsensor was made using the same procedure used with the 
external commercial RE and CE. With the new selected potential of $-600 \mathrm{mV}$, the calibration curve for the integrated configuration presented a satisfactory response of $2.07 \pm 0.07 \mathrm{nA} \cdot \mathrm{L} \cdot \mathrm{mg}^{-1} \mathrm{DO}$ with a $\mathrm{R}^{2}$ of 0.99 . Detection and quantification limits were also estimated, resulting in $0.05 \pm 0.01 \mathrm{mg} \mathrm{DO} \cdot \mathrm{L}^{-1}$ and $0.17 \pm 0.06 \mathrm{mg} \mathrm{DO} \cdot \mathrm{L}^{-1}$ respectively. These results shows a good response with the use of the integrated system, with a small loss of sensitivity and $\mathrm{L}_{\mathrm{D}}$ and $\mathrm{L}_{\mathrm{Q}}$ respect the external reference system, due the reduction potential selected and a different needle was used.

In Table 2 the main characteristics of the microneedle here described have been compared with the common commercial available dissolved oxygen microsensors, both optical and electrochemical microsensors

Table 2. Figures of merit of comparable methods for profiling of dissolved oxygen with commercial products based on microsensors

\begin{tabular}{|c|c|c|c|c|c|c|}
\hline $\begin{array}{l}\text { Method/ } \\
\text { Materials used }\end{array}$ & $\begin{array}{l}\text { Analytical } \\
\text { ranges }\end{array}$ & $\begin{array}{c}\mathrm{O}_{2} \mathrm{~L}_{\mathrm{D}} \\
\left(\mathrm{mg} \mathrm{L^{-1 }}\right)\end{array}$ & $\begin{array}{c}\text { Spatial } \\
\text { resolution } \\
(\mu \mathrm{m})\end{array}$ & $\begin{array}{l}\text { Response } \\
\text { time (s) }\end{array}$ & Comments & References \\
\hline $\begin{array}{l}\text { Electrochemical, } \\
\text { Gold electrode }\end{array}$ & $0-8 \mathrm{ppm}$ & $0.04 \pm 0.01$ & $10-50$ & $5-10$ & $\begin{array}{l}\text { - } 8 \text { Simultaneous mesurements } \\
\text { - Compatible with other } \mu \text { ISE }\end{array}$ & This work \\
\hline \multirow[t]{4}{*}{ Optical sensor } & $0-45$ ppm & $\begin{array}{c}0.015 \pm \\
0.005\end{array}$ & 50 & 10 & $\begin{array}{l}\text { - Measurements in liquid and gas } \\
\text { phase } \\
\text { - No consumption of oxygen } \\
\text { - Single measurement } \\
\text { - pH range 1-14 }\end{array}$ & $\begin{array}{c}\text { Presens } \\
\text { (www.presens.de) }\end{array}$ \\
\hline & \multirow[t]{2}{*}{$0-22.5$} & \multirow[t]{2}{*}{0.02} & $\begin{array}{c}<50 \\
\text { Tapered tip }\end{array}$ & 1 & $\begin{array}{l}\text { - fragile } \\
\text { - display photobleaching }\end{array}$ & \multirow{2}{*}{$\begin{array}{l}\text { Loligo Systems } \\
\frac{\text { (www.loligosystem }}{\text { com) }}\end{array}$} \\
\hline & & & $\begin{array}{l}140 \mu \mathrm{m} \\
\text { Flat-broken } \\
\text { tip }\end{array}$ & 30 & $\begin{array}{l}\text { - more photostable than tapered } \\
\text { sensor tips } \\
\text { - long-term stable } \\
\text { - more robust }\end{array}$ & \\
\hline & $\begin{array}{c}0-200 \\
\mathrm{mmHg}\end{array}$ & --- & 250 & $20-30$ & $\begin{array}{l}\text { - Flexible } \\
\text { - Manual temperature } \\
\text { compensation } \\
\end{array}$ & $\begin{array}{l}\text { Oxford Optroni } \\
\text { (www.oxford- } \\
\text { optronix.com) } \\
\end{array}$ \\
\hline \multirow{2}{*}{$\begin{array}{l}\text { Electrochemical } \\
\text { Clark type, gold } \\
\text { electrodes }\end{array}$} & $0-8 \mathrm{ppm}$ & 0.01 & $10-500$ & $1-3$ & $\begin{array}{l}\text { - Single measurement } \\
\text { - pH range 1-14 }\end{array}$ & $\begin{array}{c}\text { Unisense } \\
\text { (www.unisense.con }\end{array}$ \\
\hline & $0-20 \mathrm{ppm}$ & --- & 2000 & 12 & $\begin{array}{l}\text { - Probe can be plugged directly } \\
\text { into any standard pH meter }\end{array}$ & $\begin{array}{c}\text { Lazar Research } \\
\text { Laboratories } \\
\text { (www.lazarlab.com }\end{array}$ \\
\hline
\end{tabular}

Biofilm DO profile study

The suitability of the developed DO-MEA microsensor for biofilm monitoring was evaluated in a heterotrophic aerobic biofilm grown in a FPB. DO profiles were obtained using DO-MEA microsensors with both the external and the integrated RE/CE configuration, and compared to the commercial Clark-type microsensor, widely applied and validate for biofilm monitoring. The thickness of heterotrophic biofilms, typically around $1 \mathrm{~mm}$, allowed using any of the three different DO-MEA designs. The largest MEA sensor design was selected for biofilm monitoring because the $50 \mu \mathrm{m}$ electrodes due to their higher sensitivity in terms of total current and the lower detection and 
quantification limits. During the detection process, DO is consumed, however this value has been estimated to be as low as $2.5 \times 10^{-9} \mathrm{mg}$ of DO due to the micro-sized dimensions of the electrodes. Since convection inside biofilms can be neglected, the volume of biofilm affected by the measurement can be obtained using Einstein's relation $\delta=\sqrt{ }(2 \mathrm{Dt})$ (where $D\left[\mathrm{~m}^{2} \cdot \mathrm{s}^{-1}\right]$ is the DO diffusion coefficient and $\mathrm{t}=15$ seconds) is $7.1 \times 10^{-11} \mathrm{~m}^{3}$. The alteration produced by this consumption is extremely local and the biofilm is able to quickly recover its initial conditions, and so this perturbation in the oxygen concentration around the electrodes can be considered negligible.

Both sensors were tested maintaining the same position within the biofilm, for this reason a 3D micromanipulator was used. DO profiles (Fig. 4, right) were obtained by three consecutive 8-point measurements for both DO-MEA microsensor configurations (Fig. 4, left) to cover a total of 24 measurements per microsensor (Fig. 4 left). For the Clark-type microsensor, each measurement was made every $50 \mu \mathrm{m}$ using the micromanipulator.
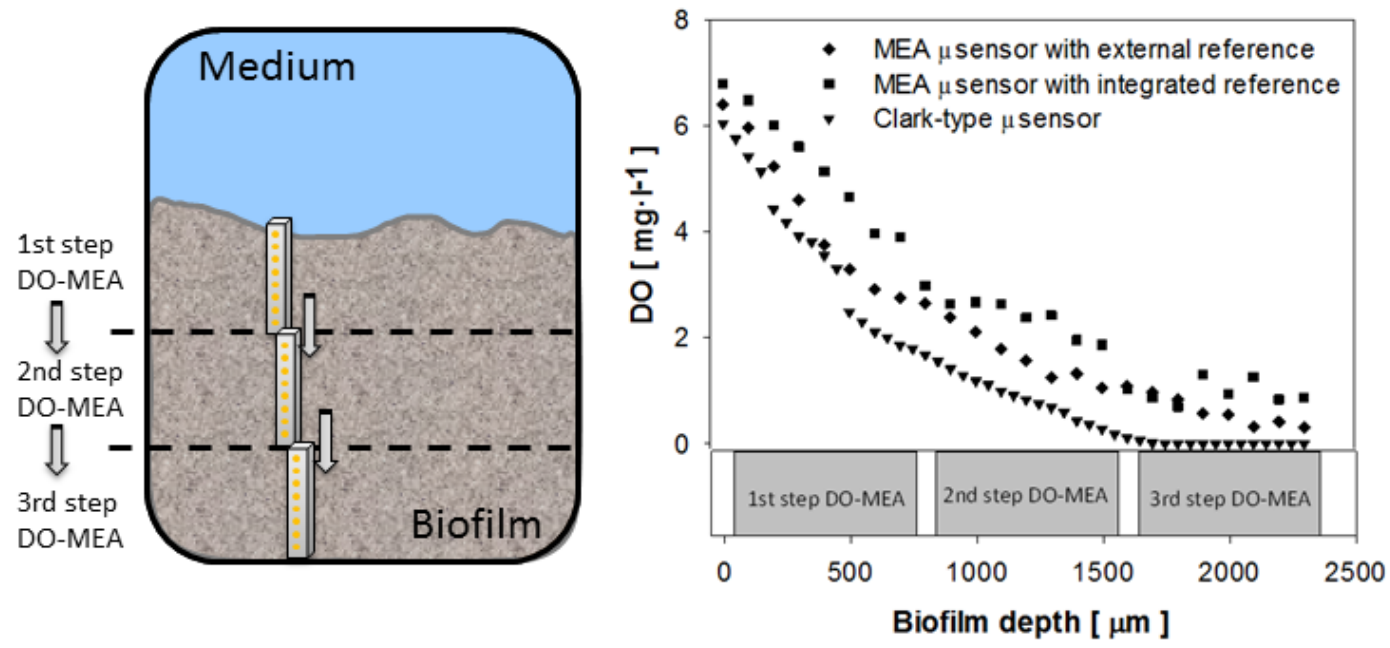

Fig. 4 Left: Schematic representation of the three consecutive DO-MEA measurements. Right: Microprofiles of DO within an aerobic heterotrophic biofilm using the MEA microsensor with external $(\downarrow)$ and three internal configurations ( $\mathbf{\square})$, and the commercial Clark-type microsensor $(\boldsymbol{\nabla})$.

The DO profiles with the different microsensors are showed in Fig. 4. The first thing to note when comparing different types of sensor is the different DO concentration measured in the liquid-biofilm interface, being $6.4 \mathrm{mg} \mathrm{DO} \cdot \mathrm{L}^{-1}$ and $6.8 \mathrm{mg} \mathrm{DO} \cdot \mathrm{L}^{-1}$ for the DO-MEA sensor with the external and the integrated reference system respectively, and $6.1 \mathrm{mg} \mathrm{DO} \cdot \mathrm{L}^{-1}$ for the Clark microsensor. These small differences in the concentration measured were maintained throughout all the profile within the biofilm, and became clear again from $1800 \mu \mathrm{m}$ depth, where according to Clark sensor oxygen was totally depleted, while both DO-MEA sensor profiles indicated that DO was not depleted after $2400 \mu \mathrm{m}$. Despite these slight differences in the measured concentrations, all sensors showed the same behavior, being able to observe the same slopes along the 
three measured DO profiles. Therefore results showed that, considering the response of Clark microsensor as a standard, DO-MEA sensor, with both configurations, detected a slightly higher DO. This fact could be explained by changes in bacteria activity at the recording time of the profiles, because these were not carried out simultaneously. However the most probable cause was the bigger dimensions of the needle width, 500 $\mu \mathrm{m}$, than that of the Clark microsensor, which altered the biofilm structure, facilitating the entrance of some of the bulk liquid to the biofilm and causing a misleading sensor reading. In order to reduce the disturbance during biofilm profiling, the DO-MEA sensor will be made of a flexible polymer, with a maximum thickness of $50 \mu \mathrm{m}$.

Overall, both sensors responses exhibited the same trend, thus confirming the suitability of the developed DO-MEA sensor for biofilm monitoring. The DO-MEA sensor also allowed obtaining the profile more easily, in three 8-points consecutives measurements, reducing the profile variations caused by the dynamics of the biofilm.

Furthermore, in the near future, the use of such microfabricated device will enable the integration of ion selective membranes, which may be deposited selectively in specific microelectrodes in a single needle. The combination of several different modified microelectrodes will enable the acquisition of a specific biofilm profile for a previously defined analytes such as for example oxygen, sodium, potassium or sulphides. These will provide to this novel platform of high versatility for obtaining desired and specific profiles for deeper studies of biofilms.

\section{Conclusions}

The technological improvement and the versatility of the standard microfabrication techniques open the possibility to multiple studies of biofilms with different thickness, even in micro scaled biofilm reactors, at a low cost per sensor and high robustness. The DO-MEA sensor showed a good performance, providing reliable instantaneous information of the activity inside biofilms. DO-MEA sensor exhibited an excellent linear response in the range $0-8 \mathrm{mg} \mathrm{DO} \cdot \mathrm{L}^{-1}$ for the three different tested designs, with diameters of $50 \mu \mathrm{m}, 25 \mu \mathrm{m}$ and $10 \mu \mathrm{m}$. The detection and quantification limits of the three designs have been determined, showing low values in all cases.

From the DO-MEA sensor characterization in different conditions and mediums, it can be concluded that the sensor may be suitable under a wide range of conditions $(\mathrm{pH}$, and mineral medium composition and concentration), widening the variety of bioapplications where it can be used.

The developed DO-MEA sensor overcomes most of the commercial Clark-type microsensors drawbacks, such as the high cost per sensor and fragility. In addition, it enables the performance of simultaneously measuring at multiple points. This novel sensor represents an essential tool to record a biofilm profile in a single measurement, reducing significantly the acquisition time of a complete profile. This sensor becomes an extremely important tool that will enable advances in biofilm characterization, obtaining mass transfer and biokinetics phenomena related information. Understanding 
of these processes will be a key issue to progress in the optimization of applied biotechnologies.

This microfabricated needle has been the proof of concept for DO sensing in this application. However, further technological improvements of these sensors are ongoing for on the one hand reduce the thickness of the needle and thus minimize the damage of the biofilm structure, and on the other hand to cover the electrode area with oxygenpermeable membranes for opening its applicability to extreme biofilm growth conditions.

\section{Acknowledgements}

This work has been founded by projects DPI2011-28262-C04 and CTM2012-37927C03/FEDER, financed by the Ministerio de Economía y Competitividad (Spain). AM gratefully acknowledges an FPI-2012 pre-doctoral scholarship, (it funded her PhD studies at Universitat Autònoma de Barcelona), and XG also acknowledges an FPI-UPC pre-doctoral scholarship, both from Ministerio de Economía y Competitividad (Spain). 


\section{References}

1. Cohen Y (2001) Biofiltration - The treatment of fluids by microorganisms immobilized into the filter bedding material: a review. Bioresour Technol 77:257-274. doi: 10.1016/S0960-8524(00)00074-2

2. Gavrilescu M, Macoveanu M (2000) Attached-growth process engineering in wastewater treatment. Bioprocess Eng 23:95-106.

3. Okabe S, Itoh T, Satoh H, Watanabe Y (1999) Analyses of Spatial Distributions of Sulfate-Reducing Bacteria and Their Activity in Aerobic Wastewater Biofilms. Appl Environ Microbiol 65:5107-5116.

4. Ning Y-F, Chen Y-P, Li S, et al. (2012) Development of an in situ dissolved oxygen measurement system and calculation of its effective diffusion coefficient in a biofilm. Anal Methods 4:2242. doi: 10.1039/c2ay25132a

5. Zhou X-H, Liu J, Song H-M, et al. (2012) Estimation of Heterotrophic Biokinetic Parameters in Wastewater Biofilms from Oxygen Concentration Profiles by Microelectrode. Environ Eng Sci 29:466-471. doi: 10.1089/ees.2010.0456

6. Denkhaus E, Meisen S, Telgheder U, Wingender J (2007) Chemical and physical methods for characterisation of biofilms. Microchim Acta 158:1-27. doi: 10.1007/s00604-006-0688-5

7. Optical methods for sensing and imaging oxygen: materials, spectroscopies and applications - Chemical Society Reviews (RSC Publishing). Chem. Soc. Rev.

8. Clark LC, Wolf R, Granger D, Taylor Z (1953) Continuous Recording of Blood Oxygen Tensions by Polarography. J Appl Physiol 6:189-193.

9. Revsbech NP, Jørgensen BB (1986) Microelectrodes: Their Use in Microbial Ecology. In: Marshall KC (ed) Adv. Microb. Ecol. Springer US, pp 293-352

10. Paliteiro C (1994) (100)-Type behaviour of polycrystalline gold towards O2 reduction. Electrochimica Acta 39:1633-1639. doi: 10.1016/00134686(94)85147-6

11. Jeroschewski P, Steuckart C, Eickert G, Kuhl M (1998) A H2S microsensor for profiling biofilms and sediments: application in an acidic lake sediment.

12. Hang Gao FS (2011) Aerobic denitrification in permeable Wadden Sea sediments. ISME J 5:776. doi: 10.1038/ismej.2010.166

13. Wu C-C, Yasukawa T, Shiku H, Matsue T (2005) Fabrication of miniature Clark oxygen sensor integrated with microstructure. Sens Actuators B Chem 110:342349. doi: 10.1016/j.snb.2005.02.014

14. Carlos de la Rosa TY (2006) Development of an automation system to evaluate the three-dimensional oxygen distribution in wastewater biofilms using microsensors. Sens Actuators B-Chem - Sens ACTUATOR B-CHEM 113:4754. doi: 10.1016/j.snb.2005.02.025 
15. Zhou X-H, Qiu Y-Q, Shi H-C, et al. (2009) A New Approach to Quantify Spatial Distribution of Biofilm Kinetic Parameters by In Situ Determination of Oxygen Uptake Rate (OUR). Environ Sci Technol 43:757-763. doi: 10.1021/es802373q

16. Kumar A, Hille-Reichel A, Horn H, et al. (2012) Oxygen transport within the biofilm matrix of a membrane biofilm reactor treating gaseous toluene. $\mathrm{J}$ Chem Technol Biotechnol 87:751-757. doi: 10.1002/jctb.3800

17. Lee J-H, Lim T-S, Seo Y, et al. (2007) Needle-type dissolved oxygen microelectrode array sensors for in situ measurements. Sens Actuators B Chem 128:179-185. doi: 10.1016/j.snb.2007.06.008

18. Davies TJ, Ward-Jones S, Banks CE, et al. (2005) The cyclic and linear sweep voltammetry of regular arrays of microdisc electrodes: Fitting of experimental data. J Electroanal Chem 585:51-62. doi: 10.1016/j.jelechem.2005.07.021

19. Menshykau D, O’Mahony AM, del Campo FJ, et al. (2009) Microarrays of RingRecessed Disk Electrodes in Transient Generator-Collector Mode: Theory and Experiment. Anal Chem 81:9372-9382. doi: 10.1021/ac9017633

20. Godino N, Borrisé X, Muñoz FX, et al. (2009) Mass Transport to Nanoelectrode Arrays and Limitations of the Diffusion Domain Approach: Theory and Experiment. J Phys Chem C 113:11119-11125. doi: 10.1021/jp9031354

21. Menshykau D, Cortina-Puig M, del Campo FJ, et al. (2010) Plane-recessed disk electrodes and their arrays in transient generator-collector mode: The measurement of the rate of the chemical reaction of electrochemically generated species. J Electroanal Chem 648:28-35. doi: 10.1016/j.jelechem.2010.07.003

22. Ordeig O, del Campo J, Muñoz FX, et al. (2007) Electroanalysis Utilizing Amperometric Microdisk Electrode Arrays. Electroanalysis 19:1973-1986. doi: 10.1002/elan.200703914

23. Lanyon YH, Arrigan DWM (2007) Recessed nanoband electrodes fabricated by focused ion beam milling. Sens Actuators B Chem 121:341-347. doi: 10.1016/j.snb.2006.11.029

24. Del Campo FJ, Abad L, Illa X, et al. (2014) Determination of heterogeneous electron transfer rate constants at interdigitated nanoband electrodes fabricated by an optical mix-and-match process. Sens Actuators B Chem 194:86-95. doi: 10.1016/j.snb.2013.12.016

25. Laczka O, del Campo FJ, Muñoz-Pascual FX, Baldrich E (2011) Electrochemical detection of testosterone by use of three-dimensional disc-ring microelectrode sensing platforms: application to doping monitoring. Anal Chem 83:4037-4044. doi: 10.1021/ac1031594

26. Sánchez-Molas D, Esquivel JP, Sabaté N, et al. (2012) High Aspect-Ratio, Fully Conducting Gold Micropillar Array Electrodes: Silicon Micromachining and Electrochemical Characterization. J Phys Chem C 116:18831-18846. doi: 10.1021/jp305339k 
27. Prehn R, Abad L, Sánchez-Molas D, et al. (2011) Microfabrication and characterization of cylinder micropillar array electrodes. J Electroanal Chem 662:361-370. doi: 10.1016/j.jelechem.2011.09.002

28. Fischer LM, Tenje M, Heiskanen AR, et al. (2009) Gold cleaning methods for electrochemical detection applications. Microelectron Eng 86:1282-1285. doi: 10.1016/j.mee.2008.11.045

29. Bard AJ, Faulkner LR (2001) Electrochemical methods: fundamentals and applications. Wiley, New York

30. Wolff CM, Mottola HA (1978) Enzymic substrate determination in closed flowthrough systems by sample injection and amperometric monitoring of dissolved oxygen levels. Anal Chem 50:94-98. doi: 10.1021/ac50023a026

31. Lewandowski Z, Beyenal H (2013) Fundamentals of Biofilm Research, Second Edition. CRC Press

32. Dorado AD, Baeza JA, Lafuente J, et al. (2012) Biomass accumulation in a biofilter treating toluene at high loads - Part 1: Experimental performance from inoculation to clogging. Chem Eng J 209:661-669. doi: 10.1016/j.cej.2012.08.018

33. Del Campo FJ, Ordeig O, Vigués N, et al. (2007) Continuous measurement of acute toxicity in water using a solid state microrespirometer. Sens Actuators B Chem 126:515-521. doi: 10.1016/j.snb.2007.03.038

34. Murphy VG, Barr RE, Hahn AW (1976) Control of Electrode Aging by a Periodic Anodization Technique. In: Grote J, Reneau D, Thews G (eds) Oxyg. Transp. Tissue - II. Springer US, pp 69-75 